Донецька область. Донецьк: КП Регіон, 2008. Ч. 1. 784 с., Ч. 2. 784 с.; Житомирська область. Житомир: «Полісся», 2008. 1116 с.; Запорізька область. Запоріжжя: Дике Поле, 2008. 1080 с.; Київська область. Біла Церква: Буква, 2008. 1376 с.; Місто Київ. К.: Фенікс, 2008. 584 с.; Кіровоградська область. Кіровоград: ТОВ «Імекс ЛТД», 2008. 920 с.; Луганська область. Луганськ: Янтар, 2008. 918 с.; Миколаївська область. Миколаїв: Вид. «Шамрай», 2008. 864 с.; Одеська область. Одеса: Астропринт, 2008. 1008 с.; Полтавська область. Полтава: Оріяна, 2008. 1200 с.; Сумська область. Суми: Собор, 2008. 920 с.; Харківська область. Харків: Фоліо, 2008. 1023 с.; Херсонська область. Херсон: Наддніпрянська правда, 2008. 844 с.; Хмельницька область. Хмельницький: ТОВ «Поліграфіст-2», 2008. Кн. 2. 1176 с.; Черкаська область. Черкаси: Вид. Чабаненко Ю., 2008. Ч. 1. 1200 с.,
Ч. 2. 1200 с.; Чернігівська область. Чернігів: Деснянська правда, 2008. 1060 с.

42. Русаков Л. Ржавчина хлебов (автореферат доклада) // Сборник ВИЗРа. 1932. Вып. 4. С. 55-57.

43. Грушевой С. Ржавчина зерновых хлебов. Проблема ликвидации и наши очередные задачи // Сборник ВИЗРа. 1933. Вып. 6. С. 51-54.

44. Борьба с ржавчиной на Украине // Сборник ВИЗРа. 1933. Вып. 7. С. 89.

45. Грушевой С.Е., Маклакова Г.Ф. Ржавчина зерновых культур и меры борьбы с нею. М.-Л.: Гос. изд. колх. и совхоз. лит-ры, 1934. 40 с.

46. Воловина О., Плохій С.М., Левчук Н.М., Рудницький О.П., Ковбасюк А.Б., Шевчук П.Є. Регіональні відмінності втрат від голоду 1932-1934 рр. в Україні // Український історичний журнал. Київ. 2017. Вип. 2. С. 76.

\title{
WEEDS, DISEASES AND PLANT PESTS AS FACTORS OF FAMINE IN 1932-1933
}

(C) 2019

\author{
Nazarenko Nazar Nikolayevich, doctor of biological sciences, \\ professor of Chemistry, Ecology and Chemistry Methodology Department \\ South Ural State Humanitarian Pedagogical University (Chelyabinsk, Russian Federation) \\ Bashkin Anatoliy Viktorovich, coordinator \\ Project «Historical Materials» (Moscow, Russian Federation)
}

Abstract. Land tenure system (individual land using and conventional farming) which had been formed in the USSR by the middle $1920^{\text {th }}$, single-crops and low farming techniques and farming chemicalization led to emergency development of weeds, diseases and plant pests. In spite of agricultural enterprises consolidation and attempts to remove farming techniques backwardness, the grain production in the USSR had been doomed for weeds, diseases and plant pests outbreak that occurred in 1932 in main cereals regions of the USSR. Consequently, catastrophic epizooties of some plant pests and catastrophic epiphytoties of weeds as well as cereal crops mycosis led to catastrophic losses of yield that took place in 1932 in main cereals regions of the USSR. The highest level of pest infestation, dockage of grain was observed in 1932, it was the cause of cereals crops baking value fall. From quarter to half of gross grain yield was off-grade and from 30 to $70 \%$ of grains were unapt for food in 1932-1933. The most sufferers were the main cereals regions - Ukraine and Northern Caucasus, where the greatest mortality was observed in 1933. Thus, weeds, diseases and plant pests were one of principal factors of crop failure and bad cereals crops baking value as well as famine in 1932-1933. In spite of high mycosis infection of grains, high mortality from mycosis intoxication wasn't confirmed.

Keywords: famine in 1932-1933; weeds; fungus diseases of cereals crops; plant pests; agricultural diseases; epiphytoties and epizooties of $1930^{\text {th }}$; phytopathology; cereals crops infection rate; cereals crops baking value; food poisonings and mortality; agrarian crisis.

\section{УДК 94(595)}

DOI 10.24411/2309-4370-2019-11211

Статья поступила в редакцию 12.01.2019

\section{КОРПОРАЦИЯ РЭНД: ДЕЯТЕЛЬНОСТЬ РОБЕРТА КОМЕРА}

(C) 2019

Лёзин Александр Иванович, студент исторического факультета

Самарский государственный соииально-педагогический университет (2. Самара, Российская Федераиия)

Аннотащия. РЭНД - «фабрика мысли» в США. Корпорация, в которой специалисты разных областей науки пишут аналитические работы, посвящённые той или иной проблеме. РЭНД имеет большой авторитет в США. Многие работы по Вьетнаму делались по государственному заказу США (от Министерства обороны), в том числе работы Роберта Комера - именно об исследованиях этого специалиста, проведённых по заказу Агентства перспективных исследований при Министерстве обороны США, и пойдёт речь. В статье просматривается биография Роберта Комера в контексте от конфликта во Вьетнаме до сотрудничества с корпорацией РЭНД. Во Вьетнаме, по личному указанию президента США Линдона Джонсона, Комер являлся руководителем «программы умиротворения», или официально: «программы поддержки гражданских операций и развития сельских районов». Завершив свою деятельность во Вьетнаме, Комер поделился накопленным опытом и знаниями в докладах для корпорации РЭНД. Работы его обращены к проблемам контрпартизанской войны. В статье даются характеристики работам Роберта Комера в рамках корпорации РЭНД. В заключение подчёр- 
кивается актуальность исследуемой темы. Из-за таких событий, как вторжение США в Афганистан и Ирак, деятельность Комера по реализации программы «CORDS» во Вьетнаме приобрела повышенный интерес у многих современных экспертов.

Ключевые слова: корпорация РЭНД; Роберт Комер; ЦРУ; война во Вьетнаме; США; Линдон Джонсон; контрпартизанская война; асимметричная война; Макджордж Банди; Вьетконг; Южный Вьетнам; Роберт Макнамара; «программа умиротворения»; Пентагон; Совет по национальной безопасности; Министерство обороны США; Агентство перспективных исследований.

РЭНД трудно обвинить в том, что корпорация была далека от конфликта во Вьетнаме или отдалённо его представляла, поскольку даже имела свой офис в Южном Вьетнаме [1, p. iii]. При этом аналитика корпорации доходила не только до специалистов Пентагона и министра обороны, но и до самого президента США. Так, в меморандуме от 28 июня 1965 г., адресованном президенту США Линдону Джонсону, Макджордж Банди, советник по национальной безопасности, даёт краткую характеристику только что завершённому исследованию РЭНД. Банди не только кратко пересказывает суть работы, но и соглашается с корпорацией. В особенности это ярко демонстрирует фраза: «РЭНД и мы убеждены...» [2, doc. 27].

Ярким доказательством может служить телефонный разговор между президентом Джонсоном и министром обороны Робертом Макнамарой, состоявшийся 17 января 1966 г. В разговоре министр обороны ссылается на труды Леона Гуре - сотрудника корпорации РЭНД, посвящённые мотивации и моральному духу Вьетконга [3-5]. Министр говорит президенту, что они наняли корпорацию РЭНД, чтобы в течение нескольких месяцев она вела обширные допросы военнопленных и перебежчиков Вьетгонга. Макнамара осмотрительно соглашается с позитивным взглядом автора, кратко пересказывает суть работы, где заключалось, что боевой дух Вьетконга начинает постепенно угасать. Он подкрепляет это фактами в виде увеличения числа дезертиров, но затем признает, что цифра не столь большая. Из главных причин он называет: болезни, питание, отсутствие лекарств и обычного отдыха. Давление США в виде воздушных военных операций начинает постепенно нарастает. Всё это сказывается на мотивации Вьетконга. При этом министр с присущей долей осторожности считает, что боевой дух не уничтожен, но растерянность в Вьетгонге начинает постепенно проявляться [2, doc. 26]. Так или иначе, но вовлеченность РЭНД в конфликт, без сомнения, очевидна.

Теперь перейдём к одному из наиболее ярких деятелей, сотрудничавших одно время с РЭНД. Роберт Уильям Комер, по характерстике Ф. Дэвидсона, генерал-лейтенанта, служившего во Вьетнаме в качестве начальника разведотдела штаба американского командования, - это великолепный политик и виртуозный бюрократ [6]. Он являлся сотрудником ЦРУ и славился жёстким темпераментом, за что и получил своё прозвище «паяльная лампа». Комер не считал себя специалистом по конкретному региону. Он позиционировал себя универсалом - неважно, ближневосточный это или западноевропейский регион.

В 1961 г. он стал помощником Макджорджа Банди в Совете по национальной безопасности США. Весной 1966 г. назначен специальным помощником президента по вопросам умиротворения во Вьетнаме. В меморандуме о действиях в области национальной безопасности № 343 от 28 марта 1966 г. Джонсон уведомляет правительственный кабинет, что назначил Роберта Комера своим специальным помощни- ком по выполнению невоенных программ для Вьетнама. В конце документа Джонсон подчёркивает, что Комер имеет право обратиться к нему напрямую, когда пожелает. Разумеется, это говорит о сильном доверии к Комеру [2, doc. 102]. Необходимо отметить, что Комер не сразу был отправлен в Южный Вьетнам, а лишь в 1967 г. [7, с. 86].

Комер стал руководителем «программы умиротворения», или официально: «программы поддержки гражданских операций и развития сельских районов» - «Civil Operations and Rural Development Support» (или «CORDS»). Программа представляла собой социально-экономическую помощь. Цель состояла в стабилизации и укреплении южновьетнамского режима [7, с. 86]. Стоимость «программы умиротворения» в самый пиковый период была меньше одного миллиарда долларов, учитывая, что на войну в целом было потрачено 28 миллиардов долларов [8, p. 48]. К сожалению, об объективности этих данных сложно говорить, поскольку цифры привёл сам куратор программы. В 1968 г. деятельность Комера во Вьетнаме закончилась, на смену ему был назначен Уильям Колби, тоже сотрудник ЦРУ. После этого Комер был направлен послом в Турцию, но проработал там недолго, по причине кадровых ротаций, устроенных новой администрацией Ричарда Никсона [9].

В дальнейшем началось сотрудничество Роберта Комера с корпорацией РЭНД. На сегодняшний день официально РЭНД опубликовала в открытом доступе восемь работ Комера. В хронологических рамках работы выполнены с 1970 по 1987 гг. - собственно, после того как Комер был руководителем программы «CORDS» во Вьетнаме и послом США в Турции. Из вышеупомянутых восьми работ, три - по Вьетнаму и одна - по малайскому конфликту. Эти сочинения посвящены проблемам контрпартизанской войны. Другие работы касаются проблем НАТО и ядерного разоружения - безусловно, можно говорить о широком спектре специалиста [10-17]. При этом показательно, что во время реализации программы «CORDS» Комер не проявлял внимания к отчётам и расследованиям РЭНД, однако это не помешало сотрудничеству с корпорацией в дальнейшем [1, p. 384].

Начнём с первого документа, посвящённого вьетнамской проблеме, под сложным наименованием: «Организация и управление "новой модели" в умиротворительной программе: 1966-1969 гг.». Эта работа была рассекречена 12 декабря 2005 г. Время её выпуска РЭНД датируется 7 мая 1970 г. Автором этого доклада является Комер, но авторство это относительное, скорей редакционное, поскольку работа в основном представляет стенограмму трёхдневного семинара РЭНД, проведённого в ноябре 1969 г. В этом семинаре приняли участие многие деятели «программы умиротворения», разумеется, не обошлось без самого Комера. Доклад является самым большим из серии четырёх документов, посвящённых контрпартизанской войне, а именно «программе умиротворения» [10]. 
Как вспоминает Комер, начало действия программы «CORDS» наступило в мае 1967 года. Необходимо отметить, именно в это время он прибывает в Южный Вьетнам. Возвращаясь к мысли автора, то, по его мнению, настоящая «программа умиротворения» в широких масштабах до «CORDS» ещё не была реализована. Впоследствии важным аспектом он считал передачу ответственности за реализацию политики умиротворения правительству Южного Вьетнама. Весьма странно, но программу «CORDS» подвергали критике за чрезмерную американизацию процесса умиротворения. Здесь Комер оперирует важным аргументом против этого обвинения, утверждая, что на тот момент, когда он покидал Вьетнам, консультантами в этой программе являлись около 5500 американцев. Число вьетнамцев, которые были связаны с программой, составляло примерно 550000 человек, то есть это соотношение - сто к одному. К 1970 году количество американских консультантов выросло до 7200 человек, но выросло и число вьетнамцев. Комер признавался, он не был доволен на сто процентов своими коллегами, проводившими работы в той или иной провинции. Тем не менее он отмечает самый высокий уровень профессионализма гражданского персонала в «CORDS» во всём Вьетнаме. Подчёркивая при этом: он один из тех, кто уделял выбору сотрудников должное внимание [10, p. 66, 114, 187, 209, 214].

Перейдём ко второму докладу. Работа называется «Влияние умиротворения на мятеж в Южном Вьетнаме». Датируется августом 1970 г. Работа готовилась к ежегодной конференции, проводимой американской ассоциацией политических наук в ЛосАнджелесе, штат Калифорния. Мероприятие проводилось с 8 по 12 сентября 1970 г. Работа затрагивает период с 1967 по 1970 гг. Этот доклад, полностью написанный Комером, представляет собой анализ специалиста и/или участника вышеупомянутой проблемы [11].

В этом опусе, по словам автора, он ставит прежде всего цель не восхваление «программы умиротворения» 1967-1970 гг., а простой её анализ, который смог бы показать, в чём заключаются её отличия от предыдущих программ. Комер утверждает: «программа умиротворения», проводившаяся с 1967 по 1970 гг., делала упор на устойчивую территориальную безопасность как основополагающий принцип, который является лишь первым этапом в данном плане. Проблема состояла в том, что военные рассматривали умиротворение как дело гражданских лиц и, по мнению автора, не обеспечивали должным образом безопасность. Главный приоритет сводился к защите сельского населения, но на практике это не соответствовало действительности. Основой программы были такие аспекты, как функционирование сельской администрации, получение медицинской помощи и образования для вьетнамцев. «Программа умиротворения» сыграла свою роль во вьетнамской войне с положительной стороны для Южного Вьетнама и США, хотя трудноизмерима, - к такому мнению приходит автор. Несмотря на все её недостатки, она способствовала кратковременной стабилизации и способности правительства Южного Вьетнама противостоять повстанческим движениям в сельских районах $[11$, p. 5-7, 12, 18].

Третья работа обращена к другой стране, но имеет общую проблему. Название доклада: «Чрезвычай- ное положение в Малайе в ретроспективе: организация успешного антиповстанческого усилия». Доклад был выпущен для РЭНД в феврале 1972 г. Работа была подготовлена для агентства перспективных исследований при Министерстве обороны по контракту № DAHC15 67 C 0142. Хоть война во Вьетнаме была почти проиграна, но малайский опыт всё ещё представлял интерес для сравнительного анализа между Вьетнамом и Малайей [12].

Последняя работа Комера, посвящённая проблемам антиповстанчества, - «Бюрократия делает свое дело: институциональные ограничения деятельности правительства США во Вьетнаме» - выпущена в 1972 г. Работа тоже создана благодаря поддержке Агентства перспективных исследований при Министерстве обороны США по контракту № DAHC1573-C-0181 [13].

Важным препятствием для США во Вьетнаме, на взгляд Комера, была дееспособность южновьетнамских режимов, которые они поддерживали. По крайней мере те режимы, которые существовали до 1968 года. Ещё автор отметил, что южновьетнамскому правительству и США приходилось концентрировать своё внимание на нескольких вещах, таких как победа над повстанцами и функционирование государства. У Вьетконга цель была только одна ликвидировать южновьетнамское правительство. Но это не единственные причины провала политики США. Их немалое количество, это констатирует сам автор. Отчёты в области «программы умиротворения» до 1967 года были субъективными и вводили в заблуждение, не давая истинной картины ситуации. Но благодаря программе «CORDS» был образован отдел исследований и анализа во Вьетнаме. Признавая при этом их слабину, автор подчёркивает: они улучшили понимание происходящего в сельской местности [13, p. 10, 72].

Подходя к анализу прошедших событий, Комер утверждал в интервью 1970 г., что во Вьетнаме необходимо было повторить опыт Кореи, а именно создать единое командование, где американцы были бы во главе [8, p. 28]. Проблема заключалась в государственной машине. Как утверждает Комер, президент Джонсон был согласен с такой идеей, но объяснил Макнамаре и ему, почему она не будет действовать: гражданские ведомства, в том числе Госдепартамент, не захотят работать под командованием военных, т.к. такого не было в истории США [8, p. 31]. Такого же мнения были и военные, по воспоминаниям Роберта Монтегю, одного из ведущих помощников Роберта Комера по осуществлению программы «CORDS», их это не устраивало: как гражданское лицо может командовать вооружёнными силами во время боевого конфликта? [18, р. 34]. Тем не менее Джонсон пошёл на частичное объединение. В декабpe 1966 г. все гражданские учреждения, работающие во Вьетнаме, были реорганизованы в единую структуру, получившую наименование «Управление гражданских операций». Но по разным причинам проект провалился.

В интервью 1971 г. Комер признался, что политика, которую он проводил во Вьетнаме, не была идеальной, и причину этого он находит в отсутствии адекватного исполнения этой политики на местах сверху донизу [19, р. 61-62]. Самой критической ошибкой, по его мнению, является поздняя реализация программы «CORDS». Вполне возможно, начав 
её намного раньше, США не пришлось бы отправлять свои войска во Вьетнам [8, p. 45]. Действительно, если верить Дэвидсону, то подобные программы не предпринимались раньше 1967 г., а это уже самый разгар военных действий [6]. Практически всё вышесказанное в разных интервью Комер детально и подробно изложил в своих работах для корпорации РЭНД.

В связи с относительно недавними событиями, такими как вторжение в Афганистан и Ирак, в США началось возрождение интереса к опыту Вьетнама и к теории и практике контрпартизанской борьбы. Часть аналитиков и военных экспертов на Западе, особенно в США, пришли в 2000-е годы к выводу, что в войне во Вьетнаме не всё было так катастрофично, как казалось ранее. В связи с этим программа Комера «CORDS» приобрела актуальность у современных экспертов.

\section{Список литературы:}

1. Mai E. RAND in Southeast Asia: A History of the Vietnam War Era, Santa Monica: RAND Corp., CP-564RC, 2010. $672 \mathrm{p}$.

2. Foreign Relations of the United States, 19641968. Vol. III-IV. Vietnam, June-December 1965 / ed.: D.C. Humphrey, E.C. Keefer, L.J. Smith. Washington: Government Printing Office, 1996.

3. Goure L. Southeast Asia Trip Report, Part I: The Impact of Air Power in South Vietnam, Santa Monica, Calif.: RAND Corporation, RM-4400/1, 1964. 19 p.

4. Goure L., Thomson C.A.H. Some Impressions of Viet Cong Vulnerabilities: An Interim Report, Santa Monica: RAND Corp., RM-4699-1-ISA/ARPA, 1965. 94 p.

5. Goure L., Russo A.J., Scott D.H. Some Findings of the Viet Cong Motivation and Morale Study: JuneDecember 1965, Santa Monica: RAND Corp., RM4911-2-ISA/ARPA, 1966. 46 p.

6. Дэвидсон Ф.Б. Война во Вьетнаме. М.: Изографус, Исток, 2002. 816 с.

7. Тимошенко А.Г. «Путь в трясину» или «Свет в конце тоннеля»? Эскалация военных действий США во Вьетнаме (1965-1967 гг.) // Вестник Томского гос. ун-та. 2012. № 364. С. 84-90.

8. Oral history transcript, Robert Komer, interview 2 (II), 8/18/1970, by Joe B. Frantz, LBJ Library Oral His- tories, LBJ Presidential Library [El. resourse] // https://discoverlbj.org/item/oh-komerr-19700818-2-94-2.

9. Weiner T. Robert Komer, 78, Figure in Vietnam, Dies // New York Times. 04.12.2000.

10. Komer R.W. Organization and Management of the New Model Pacification Program: 1966-1969, Santa Monica: RAND Corp., D-20104-ARPA, 1970. 259 p.

11. Komer R.W. Impact of Pacification on Insurgency in South Vietnam, Santa Monica: RAND Corp., P4443, 1970. 19 p.

12. Komer R.W. The Malayan Emergency in Retrospect: Organization of a Successful Counterinsurgency Effort, Santa Monica: RAND Corp., R-957-ARPA, 1972. 98 p.

13. Komer R.W. Bureaucracy Does Its Thing: Institutional Constraints on U.S.-GVN Performance in Vietnam, Santa Monica: RAND Corp., R-967-ARPA, 1972. 179 p.

14. Komer R.W. Treating NATO's Self-Inflicted Wound, Santa Monica: RAND Corp., P-5092, 1973. $16 \mathrm{p}$.

15. Komer R.W. Bell C.F., Boyd E., Mcchrystal H.J., Schneider R.L., Schwab E.L. Rationalizing NATO's Defense Posture, Santa Monica: RAND Corp., R-1657ARPA/ISA/PAE, 1975. 345 p.

16. Komer R.W. Needed: Preparation for Coalition War., Santa Monica, Calif.: RAND Corp., P-5707, 1976. $10 \mathrm{p}$.

17. Komer R.W. Strategic impact of abolishing nuclear weapons, Santa Monica: RAND Corp., P-7358, 1987. $6 \mathrm{p}$.

18. Oral history transcript, Robert M. Montague, interview 1 (I), 9/27/1985, by Ted Gittinger, LBJ Library Oral Histories, LBJ Presidential Library [El. resourse] // https://discoverlbj.org/item/oh-montaguer-19850927-108-17.

19. Oral history transcript, Robert Komer, interview 3 (III), 11/15/1971, by Paige E. Mulhollan, LBJ Library Oral Histories, LBJ Presidential Library [El. resourse] // https://discoverlbj.org/item/oh-komerr-19711115-3-94-3.

Исследование выполнено за счет гранта Российского научного фонда (проект № 17-78-20029).

\section{RAND CORPORATION: ROBERT KOMER ACTIVITIES}

(C) 2019

Lyozin Alexander Ivanovich, student of History Faculty

Samara State University of Social Sciences and Education (Samara, Russian Federation)

Abstract. RAND Corporation is a «think tank» in the USA. It is a corporation in which experts of different fields of science write analytical works devoted to that or other problem. RAND has strong authority in the USA. Many works on Vietnam were done by the state order of the USA (from the Ministry of Defense), including Robert Komer's works (conducted by the request of the Defense Advanced Research Projects Agency at the U.S. Department of Defense). It is the research of this expert that is discussed in this paper. The paper looks at the biography of Robert Komer in the context from the conflict in Vietnam to cooperation with the RAND Corporation. In Vietnam, on the personal instructions of the US President Lyndon Johnson, Komer was the head of the program of «appeasement» or officially: the program of «Civil Operations and Revolutionary Development Support» (CORDS). Having completed his activities in Vietnam, Komer shared his experience and knowledge in reports for the RAND Corporation. His works are addressed to the problems of the counterpartisan war. The paper describes the work of Robert Komer in the framework of the RAND Corporation. In conclusion, the relevance is emphasized. Due to the events such as the US invasion of Afghanistan and Iraq, Komer's activities in the implementation of the CORDS program in Vietnam have gained increased interest from many modern experts.

Keywords: RAND Corporation; Robert Komer; CIA; Vietnam War; USA; Lyndon Johnson; counterinsurgency; asymmetrical war; McGeorge Bundy; Vietcong; South Vietnam; Robert McNamara; program of «appeasement»; Pentagon; National Security Council; United States Department of Defense; Defense Advanced Research Projects Agency. 